ers of this candy are splendid customers in other lines and many of our best ones started in this way.

From a business of practically nothing in 1906 to nearly $\$ 10,000$ in 1913 and 1914 showing a healthy gain over 1913 is what the methods outlined have done for my firm.

From this you can easily see why I am enthusiastic over candy as a side line. I am anxious to do more and welcome any criticism or new ideas you may offer. I thank you.

To-day I find nearly as much candy sold at $\$ 1.00$ a pound as is sold at 80 cents.

\title{
CALENDARS AS AN ADVERTISING MEDIUM FOR RETAIL PHARMACISTS.
}

FRANKLIN M. APPLE, PHAR, D.

Business has been designated by some authors to be a friendly warfare, but the conditions that confront us to-day in mercantile transactions force us to believe that it can be more appropriately termed fierce warfare for the almighty dollar.

It is almost obligatory that merchants resort to some form of advertising in order to give due publicity to their establishments and wares. Incidentally it may be stated that many professional men are not averse to having the attention of the public directed to their talents by divers methods other than the usual manner of attracting the notice of the public, demonstrating an universally acknowledged necessity for advertising of some character or description, in accordance with one's code of ethics or business principles.

A great multiplicity of mediums for giving publicity to one's wares and mental equipment are available to-day, and one is frequently perplexed when endeavoring to arrive at a decison as to the most appropriate and the most effective one to employ-taking into consideration the very vital question of cost of said form of publicity.

Having experimented with various advertising mediums years ago, I found that calendars gave me the most desirable and effective method of appealing in a dignified manner to my neighbors for their support and patronage.

Calendars have the advantage of being up-to-date each day of the entire year, making a daily appeal for the consideration of those who may gaze upon them, and we well know that no home is too humble or too aristocratic to welcome the presence of a fitting, valuable and attractive calendar of proper size and color, clearly printed.

You will kindly observe that I have stated several qualifications for the model calendar, all of which I deem essential to its effectiveness, through continued use in the homes of one's patrons.

The size I have chosen ( $5 \frac{1}{2}$ in. $x 9$ in.) is one that can with propriety and pleas- 
ure be given a space upon the wall in any room in the house, and its color,white, with black type-will not offer any drawbacks to its hanging anywhere.

The printing should be clear, with as bold faced type as will harmonize with any cut that may appear thereon; and the calendar pad should be such that the dates can readily be read by anyone of average eyesight. Bold faced type should be used to the limit of the dimensions of the pad itself.

Being engaged in the drug business, I sought for a cardboard of the size desired, upon which was printed a scene that would be appropriate to and suggestive of my business, which I reasoned would add materially to its effectiveness. My search was rewarded, by accident, by the appearance upon the scene of a salesman who represented one of our foremost, world-wide famed firms of lithographers, who prepare programs and invitations for many pharmacy schools. His line of samples included a number of prints that were of the proper size to meet my demands, and appropriately suggestive of pharmacy, as I kept constantly in mind the idea of distinctive advertising of a drug store.

Just as it is appropriate and more effective for a bank to use a print suggesting security and safety in its advertising, so it is with a print descriptive of pharmacy to advertise our business and profession. The central idea being to call attention to the fact that it was from a drug store that the calendar was received; and if it is properly prepared it will be given a space in the home.

Having a variety of prints from which to select made it possible to use a series of them, one each year, making a set that has been preserved by some of my patrons for years.

It will be observed that one of these prints appears to have been prepared specially for my use, whereas the facts are that it was a stock plate that was altered, without extra cost to me, to serve my purposes. You can imagine the effect such an apparently individual calendar had upon my patrons, leading them to believe it to be a very costly one, the result of personal study and design; also adding to the value of succeeding ones.

Persistency of advertising has been stated to be essential to the effectiveness of the effort to attract and retain trade; and by adhering to this form of distinctive advertising, we have been able to reap a satisfactory reward from our efforts and expenditure along this line.

In order to make our calendars more valuable to our patrons, therefore adding to the possibilities of their retention and use by the customer daily, we have had printed upon the reverse side thereof some information that quite likely would appeal to the members of the household and which they wished to preserve in a convenient place. What more convenient place to have it than upon the daily calendar, which they would not be likely to misplace or store away somewhere to be soon forgotten?

You will undoubtedly think that the cost of this very high-grade, appropriate, suggestive and effective advertising is extremely high, but I can assure you that I have found it to be very reasonable, considering the results obtained from its use.

Probably it has become apparent to you by this time that it is vital that careful thought be given to the selection of an advertising medium and that the minor 
details of the one selected be not overlooked in order to reach the desired end, with the richest harvest as a reward for your efforts.

Lay out your plans for an advertising campaign as a general lays out his plans for a battle and you will not run a very great risk of squandering your appropriation for publicity; and don't overlook the possibilities of the calendar as an advertising medium for retail pharmacists.

\title{
"WHAT ADVERTISING METHODS DO WE EMPLOY?"
}

\author{
R. A. LEET, OAKLAND, CAL.
}

In the first place we employ an advertising expert to advise us as to the mediums to be selected and the extent to which each shall be made use of. We also arrange that he shall attend to all of the details incidental to the carrying out of our advertising program. It is then assured that copy will be changed regularly, and that seasonal advertising will be looked after at the proper period. Regular interviews are arranged for with our advertising manager to furnish him material for copy, and enough matter is always kept ahead so that the change of copy shall occur without interruption, even though an interview or two should be missed. The advertising man is given freedom to consult with certain of the employees in order to get the real local color and atmosphere to his announcements and descriptions.

He is expected to see that a circular, descriptive of the drug store articles that would interest the mother of a very young child, goes each month to the birth list. $\mathrm{He}$ is expected to see that vacation suggestions, on a circular that can be checked off and used as a shopper's memorandum, gets into the hands of practically all of the people who take vacation's and might use our stores. He is expected to have a circular pertaining to seasonable items ready for each month's statements, and circulars to go out in the packages to boost the sale of our specialties. He is supposed to keep track of the special occasions on the calendar and to have appropriate reference to them in our advertisement when business can be thereby promoted. He is also supposed to supply the copy for the "hoid up" publications-those programs and year books, etc., that you don't consider to be worth much of anything to you for advertising mediums, but which, for certain reasons, you can't get out of patronizing. These usually require of the man, who is not an advertising specialist, the making up of extemporaneous copy-copy that must be ground out while the solicitor waits, and while your mind is distracted with other thoughts. But your advertising man will suit the copy to the medium and get some value for you even from this sort of advertising.

The thing that $I$ would like to make the strongest in this paper is the advantage that lies in having an advertising man who has no other duty, so far as your business is concerned, except to look after your advertising. I don't think any business should attempt to do any advertising until it can be safely assured that 